\title{
Theory for Financial Controlling in Corporations in the Modern Environment
}

\author{
Viktoriya Valeryevna Manuylenko, ${ }^{1,2, *}$, Marianna Aslanbekovna Shebzukhova ${ }^{1}$ \\ ${ }^{1}$ Institute of Economics and Management, Department for Finance and Credit, North Caucasus Federal University, 1 Pushkin str., \\ Stavropol, Russia \\ ${ }^{2}$ Faculty for Regional Development, Department for Regional Economics, Russian Technological University, Stavropol Branch, 8 \\ Kulakov Prospect, Stavropol, Russia
}

Received June 23, 2021; Revised July 20, 2021; Accepted August 27, 2021

\section{Cite This Paper in the following Citation Styles}

(a): [1] Viktoriya Valeryevna Manuylenko, Marianna Aslanbekovna Shebzukhova, "Theory for Financial Controlling in Corporations in the Modern Environment," Universal Journal of Accounting and Finance, Vol. 9, No. 4, pp. 773 - 782, 2021. DOI: 10.13189/ujaf.2021.090423.

(b): Viktoriya Valeryevna Manuylenko, Marianna Aslanbekovna Shebzukhova (2021). Theory for Financial Controlling in Corporations in the Modern Environment. Universal Journal of Accounting and Finance, 9(4), 773 - 782. DOI: 10.13189/ujaf.2021.090423.

Copyright $\bigcirc 2021$ by authors, all rights reserved. Authors agree that this article remains permanently open access under the terms of the Creative Commons Attribution License 4.0 International License

\begin{abstract}
Lack of theoretical and methodological grounds to formulate essential characteristics of "financial controlling" in corporations makes it difficult to efficiently conduct it in practice. It is believed that the conceptual terminology and definitions should be reflected in the methodological toolkit that determines corresponding values. Accordingly, determination of the economic content, classification of the types, forms and methods of financial controlling in corporations are the necessary elements for building methodological basis for its conduct. In this regard, it is important to correctly formulate theoretical and methodological provisions of the financial controlling in corporations and take into account development of economy. All this underlines relevance of this study. The purpose of this study is to substantiate potential development areas for the existing methodological tools related to "financial controlling" in corporations revealing economic, essential and substantial characteristics of the concept. Based on the general scientific and special methods, such as inductive, deductive, analysis, synthesis, system thinking, detailing, generalization, grouping, formalization, abstract-logical, the essence of the concept of "financial controlling" in corporations was identified considering theoretical and methodological approach. The theoretical provisions are expanded and improved for classification and interconnection of different types and forms of financial controlling. The theoretical and methodological synergetic
\end{abstract}

links of the concepts related to the financial controlling, as well as its types, forms, and methods are characterized, which will provide the ground for development of methodological toolkit for its successful implementation in the future.

Keywords Digital Controlling, Self-control, Risk Controlling, Alternative Types, Special Methods

\section{Introduction}

In the modern market environment, financial controlling represents one of the methods, techniques and tools for finance management in corporations. The theoretical and methodological studies of financial controlling in corporations as an economical essence reveal that methodological approaches to the conduct of financial controlling do not clearly reveal its characteristics, classification of forms and types that differ in Russian and foreign financial practice. Still, international and Russian economists have not sufficiently investigated the connection between the concepts of "financial control" and "financial controlling" in corporations. Some economists refer to these concepts as identical. Financial controlling types include such little known management tool like risk controlling, which is at 
its early development stage, also no certain attention is given to corporate tax controlling - there is no complex controlling model that would integrate strategic controlling, operational controlling, risk controlling, situational controlling and etc.

Russian managers, while setting strategic goals, not always have a chance to achieve them due to the lack of a certain methodological toolkit for financial controlling in corporations. At the same time, the current stage of digitization of economic processes necessitates introduction of digital forms, types and methods of financial controlling in corporations. Low theoretical and methodological attention to the issue related to creation of the tools for financial controlling in corporations diminishes efficiency of its practical implementation. In this regard, substantiation of the theoretical and methodological provisions for generation and development of a special toolkit for financial controlling conduct in corporations with its subsequent efficient implementation can be an important issue for international and national financial science and practice. Finding a relevant solution in this area is an important task of scientific researches, hence, the topic of the current study was found significant.

Achieving the goal of the study involved accomplishment of the following objectives:

- research of the essential characteristics of "financial controlling" concept;

- identification of the logical links between the concepts of "financial controlling" and "financial control";

- studying types and forms of financial controlling distinguishing standard and advantageous ones along with presenting the author's opinion;

- substantiation of the methodological toolkit for financial controlling conduct in corporations that integrated standard and advantageous types for its methodology commencement and enhancement; bringing up discussion on preferences of systematic approach focused on a synergistic effect.

The theoretical and methodological basis of the study is grounded in the works of international and Russian scientists, recognized experts in the field of financial management and financial controlling. The methodological basis of the study represents systematic, process based and logical scientific approaches to financial controlling processes in corporation aimed at the efficient results.

The working hypothesis of the study is based on the conceptual provision stating that modern theoretical and methodological means of financial controlling in corporations should be grounded in the appropriate framework of categories that meets requirements for their further improvement.

The theoretical significance of the study lies in deepening and expanding the theoretical knowledge on: essential system characteristics, classification of the types and forms of financial controlling in corporations, and processes of its conduct based on the combination of general and special methods. Certain theoretical and methodological aspects of this study can be applied as educational and methodological materials for certain subjects in educational programs, as well as for the advanced training of specialists in financial area.

Practical significance of the study lies in the application of the main theoretical and methodological provisions which incorporate the world's best practices, for commencement of a practical framework for the conduct of financial controlling in corporations.

\section{Literature Review}

Works by Russian authors: Yu.P. Aniskina, A.M. Pavlova [1], E.M. Korotkov [2] etc., considered mainly traditional types of financial controlling, i.e. operational and strategic.

Foreign authors, in contrast to the Russian ones, studied financial controlling to a greater extent and in various modifications. M. Sedliacikova, V. Vacek Z E. and Sopkova [3] reviewed financial controlling in small and medium-size enterprises in Slovakia and proposed its framework model. Ye. Wenhui, Dong Jingjing [4] in their study of Haier financial control model supported joint evolution of products, services and employees' competencies. Non-standard approach by B. Giovanni, M. Paolo [5] revealed chaos control with reference to the speculative bubbles, which can be managed by means of the control policies algorithm for chaotic dynamics. Hampson P. Daniel and G. Shiyang, X. Yi [6] referring to attribution theory stated that the external locus of control enhances the influence of consumers' trust in the country. Chinese researchers Li Yuanhui, Li Xiao, X. Erwei, H G. Dadrian [7] found that financial complications affect the selection of the profit management methods and determine the quality of internal control. Internal control, according to the Chinese authors, moderately affects interconnection of financial crisis and profit management, bounding management towards accrual basis and regulation of real profits, especially in financially troubled companies. M. Zachariadis, G. Hileman, and Susan V. Scott [8] developed elements of digital controlling, offering management and control in distributed ledgers and consider challenges of block chain technology in financial services.

Foreign researchers paid special attention to development of an alternative financial controlling type, i.e. self-control, which is at an early development stage in Russia. C. Strömbäck, T. Lind, K. Skagerlund, D. Västfjäll, G. Tinghög [9] studying the connection of self-control, financial behavior and financial well-being found that people with higher self-control tend to have 
better overall financial behavior, they are less stressed about their financial issues and feel more secure about their current and future financial situation. C. Strömbäck, K. Skagerlund, D.Västfjäll, G. Tinghög [10] justified that it is self-control rather than objective indicators related to executive function forecasts financial behavior and well-being. K. Sekścińska, Joanna Rudzinska-Wojciechowska, D. Jaworska [11] referred to self-control, its' role and influence at risky financial decisions. They noted that past success or failures analysis in self-control influences subsequent financial decisions. Thus, self-control analysis of success reduces tendency to financial risks, whereas self-control analysis of failures prompts risk prone financial decisions. Some international researchers A. P. M. Monteiro, J. A. M. Vale, C.L. M. Cepêda, E. M. de Almeida Leite [12] pay special attention to investigation of the internal control system quality and efficient decision-making considering quality of financial information. Special attention should be paid to the study by S. K. Dey, D. Sharma [13] on how corporate governance and financial performance interrelate with reference to Indian banks practices, given that, historically bank-corporations were pioneers in creation and development of theoretical and methodological aspects of controlling.

Taking into account the above, importance of researches by foreign authors on development of such advanced types of financial controlling as risk controlling, self-control, etc. cannot be underestimated for the Russian corporations. Their adjustment may gradually improve, develop and bring financial controlling in corporations to a new level, providing optimal synergy of international and Russian best practices.

\section{Method}

\subsection{Essential Characteristics of "Financial Controlling" Concept in Corporations}

International scholars while interpreting the concept of "financial controlling" in corporations pinpoint its current and strategic nature. Recognizing that definition of "financial controlling" concept in corporations includes the current and strategic components, the instrumental and methodological tool of the study includes general scientific and special methods: analysis, synthesis, detailing and generalization, grouping, formalization, analogy; inductive, deductive, abstract logical, monographic and comparative methods.

R. Mann and E. Mayer [14] considered the concept of "financial controlling" as a separate course of economic work combined with financial and economic functions in management in order to achieve operational and strategic tasks.

Russian economists - Yu.P. Aniskina and A.M.
Pavlova [1] - considered "financial controlling" as a complex system that integrates planning, analysis, and deviation control over the current indicators' values with regards to the planned ones. Apparently, such an interpretation has theoretical and methodological nature, since it reflects the methods of financial controlling.

According to E.M. Korotkov [2], "financial controlling" represents practical management associated with identification of delicate signals, timely elimination of deviations, ensuring stable strategic development in accordance with the plan or goals.

Philosophical definition of "financial controlling" concept is presented by A.M. Karminsky, S.G. Falko, A.A. Zhevaga, N. Yu. Ivanova [15] who name it as philosophical style of management thinking aimed at the efficient utilization of resources and improvement of corporations in the future.

T.A. Zolotko [16] characterized the concept of "financial controlling" as routine stage of financial management in enterprises that involves methods, techniques, and financial management tools.

According to R. Adams [17] and V.V. Burtsev [18] "financial controlling" is a form of internal control that to the greatest extent - integrates financial control means and the most important areas of corporate activities, which also timely detects deviations of the actual indicators' values from the planned ones.

The term "financial controlling" derives from the term "control", still definitions of both remain debatable. It is notable that the ending "ing" in English language significantly changes the meaning of the initial verb and turns action into a durable process. Respectively, financial controlling was interpreted by domestic and foreign scientists as "long-term control".

M.A. Vakhrushina [19] looked into the essence of controlling through accounting management and considered that financial controlling is tantamount to financial control. Such point of view narrows the substance of the latter and defines it through a system of various control forms and methods. The scientist-economist noted similar functions of control and controlling, classifying specific position of investigated financial instruments as "at the intersection of accounting, information support, and control and business coordination". That makes financial control a certain component of financial controlling.

I. V. Pogodaeva, I. T. Kovalenko [20], studying financial controlling, defined it as an integral part of a financial control form, and considered it necessary to focus primarily on bottlenecks that require attention. At the same time the main defined criterion is deviation of actual values from the planed ones and detection of inaccuracies shortly. It is encouraging that the scientists researched both concepts in interaction and demonstrated where they work together.

Financial controlling involves planning, setting 
corporations' goals, analysis, information management and, subsequently, creation of management recommendations for competent administrative decision making. That works for a corporation reaching higher level of complex management, adjusting designated goals for the current and future financial periods. Financial controlling is not fully narrowed down to the internal financial control in corporations, but stands up as an efficient mechanism that works to balance compiled information system, financial analysis functions, financial planning and internal financial control. Financial controlling as a part of corporations' financial management, in our opinion, is focused on integration of all management objectives. Tools and models of financial controlling are aimed to "create future" and manage future to ensure long-term performance of a corporation.

Financial control, on the contrary, is a standard and continuous data processing with focus on the past that identifies deviations between planned and actual values of indicators. That identifies possible misaiming, detects discrepancies and errors.

In view of the above, it is obvious that the financial terms "financial controlling" and "financial control" are interpreted as independent concepts. This fact speaks in favor of their possible intersection.

In contemporary environment, in our opinion, it is preferable to develop a comprehensive description of the concept of "financial controlling" in corporations as a system of financial management that timely identifies and prevents threats taking into account external and internal factors in condition of uncertainty and risk. That requires application of methods that convert activities of corporations' divisions into efficient performance adapted to future changes and generally intended to ensure achievement of efficient operation of corporations.

During conduct of financial controlling in corporation, it is rational to study classification of its forms and types, which determines the next stage of the study.

\subsection{Classification of Forms and Types of Financial Controlling in Corporations: Traditional and Alternative Points of View}

M.A. Pavlenkov [21] defined the form of controlling by means of its arrangement and the order of its implementation in enterprises' management. Accordingly, the form of financial controlling represents its arrangement that includes specific articulation of control activities, whereas the type means a complex of financial controlling forms set to achieve the goals. Selection of financial controlling forms introduced to corporation management primarily depends on corporation's size, regional specifics, and etc. The combination of forms and types of financial controlling in corporations is viewed as follows:
- Traditional: type - strategic, form - strategic planning, operational - internal control, risk controlling monitoring;

- alternative: type - situational, form - logical-linguistic model, external - analysis, self-control - observation, tax - tax control, planning, digital - block chain, Big Data, artificial intellect, cloud technologies, SaaS, machine learning and etc.

Traditionally, considering the split of financial controlling goals into strategic (long-term) and operational (short-term), financial controlling in corporations is also distinguished as strategic and operational.

Strategic controlling that coordinates the functions of strategic planning, control and information support systems is aimed at efficient employment of existing advantages and pushing forth potentials for successful performance of corporations in the future, and so it is acting as a tool for internal management analysis during the process of developing strategies or identifying strategic goals and objectives.

Operational controlling assumes that strategic goals are achieved regularly, i.e. annually via development and implementation of the corporations' operational goals. Corporations gradually fulfill their strategic goals by setting and achieving short-term goals within the terms of the correct strategy. Operational controlling coordinates the processes of short-term planning, control, accounting and reporting and supports up to date information system in corporations.

According to S. G. Falko [22], strategic controlling is aimed to analyze the strengths and weaknesses, opportunities and threats in corporations. Operational controlling relies on internal sources of information. Its main goal is to arrange the system to achieve financial goals of corporations.

Actors of external controlling are the specialists with the certain theoretical background and with practical experience in a particular area of financial and economic activity, i.e. those are controllers. External controlling is aimed at identification of negative deviations in management activity at all levels.

In modern environment, financial controlling in corporations is distinguished by its activity, rapid growth and variable application. Modern analytical tools are being created - that implies allocation of alternative forms and types of controlling, i.e. risk controlling, situational controlling, self-controlling, tax controlling, digital controlling, and etc.

In the international practice, an integral part of financial controlling is risk controlling, which in many cases is applied to identify shadow transactions. E. A. Gorelchenko [23] called risk controlling "a controlling subsystem that coordinates planning and risk control, providing general management and risk management in organization with information about risks." 
Subject to the above, V.V. Manuylenko, M.A. Shebzukhova [24] conclude that risk controlling is a constituent part of financial controlling and represents method and instrument for regulating shadow operations in general. Risk controlling system should penetrate corporations entirely via continuous monitoring, which is the process of constant scrutiny over the controlled values of indicators, determining deviations and identifying their causes. Based on the monitoring results, the efficiency of risk controlling system can be assessed in terms of the set goals in a corporation.

N. G. Danilochkina [25] defined situational controlling with the phrase: "what should be done if something goes wrong" and suggests correlation of the short-term and strategic plans implementation. The purpose is to determine the causes of deviations and propose certain counteractive activities. I.e. situational controlling is an independent functional course of the corporate leadership activities, which ensures competent and efficient both strategic and operational decisions in unpredictable environment, where those are based on the analysis of information aroused from the projects' environment, and the character of their subsequent generation. The form of situational controlling in corporations is a logical-linguistic model which determines the goals of the process, evaluates the environment and management principles associated with achievement of these goals in the relevant economic environment. Nonetheless, situational controlling according to the available assessment of strengths and weaknesses should ensure arrangement of qualified information support in a corporation.

Self-control is closely connected with external controlling. Its actors (owners and top managers of corporations) correct errors and improve the shortcomings of external controlling. Small corporations with insignificant financial potential tend to apply self-controlling, whereas large corporations tend to rely on external controlling.

One of the most influential factors in the external environment for corporations is tax duty. It implies competence in tax management and requires correct decisions in order to obtain positive financial results. Thus, that suggests arrangement of tax controlling. It is important to build tax controlling into financial controlling system in corporations as a structure that manages tax flows.

In digitization environment it is necessary to develop digital forms of financial controlling in corporations which are grounded in digital technologies and digital decision making (block chain, Big Data, artificial intelligence, cloud technologies, SaaS, computer learning). These forms aim to move financial controlling to a new level. They contribute solutions for strategic development issues and ensure integration of digital technologies into strategic platform solutions. "Digital controlling" as a term is used by N.S. Necheukhina, N.A. Polozova and T.A. Buyanova [26]. In their opinion, digital technologies in audit and controlling systematize and summarize information flows with no general source of origin further merging them, allowing one to get a new or predictive model suitable for development of a strategy and management tactics that can be applied as in large industrial corporations and in small industries. Transition to the digital economy will ensure development of the highest level of the accounting, control and analytical management systems in corporations contributing to creation of digital forms of financial controlling.

Thus, the authors identified and described traditional and alternative types as well as corresponding forms of financial controlling in corporations. The forms and types of financial controlling in corporations determine methods of financial controlling.

\subsection{Validation of Methodological Toolkit for Financial Controlling Conduct in Corporations}

Taking into account that financial controlling is a part of economic controlling it is obvious that it is based on the same methods, techniques and tools, so they can be selected specifically by the choice of management for each corporation individually, taking into account its size or the type of business.

D. A. Batalov, M. S. Rybyantseva [27] defined method as a way to achieve financial controlling goal by means of integrating a complex of theoretical and practical knowledge by the financial controlling actor.

General methods of financial controlling in corporations in different countries can be described as follows:

In Russia, the following methods are used: analysis of risks, competition; portfolio, financial; PEST, SWOT, CVP, XYZ, ABC-analysis; BSC; a BCG matrix; budgeting; benchmarking with regards to corporations, holdings, industrial and financial groups and large diversified companies.

In Germany, corporations, holdings, industrial and financial groups and large diversified companies apply McKinsey matrix; Porter's competitive advantages analysis, break-even point analysis, actual cost; SWOT analysis and budgeting.

In Poland, small and medium-sized businesses and large corporations use SWOT-analysis; break-even point analysis, risks and deviations analysis.

In the US, corporations, holdings, industrial and financial groups, large diversified companies apply benchmarking; BCG matrix; SWOT - analysis; analysis of expenses by accounting and reporting centers.

I.S. Plakidin [28] noted that in Germany large corporations and holdings are highly interested in financial controlling promotion. Indirect expenses in German corporations are significantly high due to the 
growth of personnel costs, wages, expenses for business trips, and replacement of manual labor with automated technologies - that explains focus of financial controlling on actual costs and budgeting. Efficiency of financial controlling methods introduction is confirmed in developed countries (Germany and the USA) as well as in Poland, where most corporations define Microsoft Excel as a tool for its information support.

In practical terms, the substance of financial controlling methods fully depends on the purpose of its types. Accordingly, the scholars identify methods of controlling as strategic, operational, etc. Analysis of risk, competition and portfolio; PEST-, SWOT-, CVP-analysis, BCG matrix, synthesis, long-term forecasting and planning conclude methods of strategic financial controlling, whereas budgeting, financial analysis, ABC - analysis, synthesis, benchmarking, short-, medium-term planning represent short term financial controlling.

E.V. Ponomareva [29] noted that international financial practice, in contrast to Russian, presents following most popular portfolio analysis methods: Ansoff matrices, Porter competition models, Boston Consulting Group (BCG) matrix models, McKincey - General Electric multi factor.

Thus, it is obvious that Russian corporations should develop and apply financial controlling methods taking into account the best foreign practices that should ensure synergistic effect.

\section{Results}

\subsection{In Theoretical Block of the Research:}

The following conceptual approaches to "financial controlling" in corporations were found: process oriented - R. Mann, E. Mayer [14], system based Yu.P. Aniskina, A.M. Pavlova [1], philosophical A.M. Karminsky, S.G. Falko, A.A. Zhevaga, N.Yu. Ivanova [15], process-system oriented - T.A. Zolotko [16], combining financial controlling and internal control - R. Adams [17], V.V. Burtsev [18], practical - E.M. Korotkov [2].

- the preference given to a system based conceptual approach to "financial controlling" in corporation was proved since it integrates process, system, philosophical, process-system, practical approaches in various forms, as well as combines financial controlling and internal control;

- the comparison of the concepts of "financial control" and "financial controlling" was carried out in accordance with such criteria as characteristics, purpose, objects, actors, application results - Table 1;

Table 1. Comparison of the concepts of "financial control" and "financial controlling" in corporations

\begin{tabular}{|c|c|c|}
\hline $\begin{array}{l}\text { Comparison } \\
\text { criteria }\end{array}$ & Financial control & Financial controlling \\
\hline Characteristics & $\begin{array}{l}\text { Process implemented by the management in corporations or } \\
\text { other employees to obtain information on implementation } \\
\text { of assigned tasks: compliance with laws and regulations, } \\
\text { efficiency and rational activities and reliable reporting. }\end{array}$ & $\begin{array}{l}\text { Control conception that focuses control functions on the } \\
\text { most significant aspects of the corporation's activities, } \\
\text { in addition, defines deviations of current values from } \\
\text { the planned indicators' values and provides efficient } \\
\text { decision making that ensures improvement. }\end{array}$ \\
\hline Purpose & $\begin{array}{l}\text { Forecast of probable violations and deviations, and their } \\
\text { elimination. }\end{array}$ & $\begin{array}{l}\text { Maintenance of structure liquidity and liquid reserves. } \\
\text { Timely mobilization of financial flows and their } \\
\text { efficient reallocation to prioritized activities in } \\
\text { accordance with strategy. } \\
\text { Development, coordination, implementation of } \\
\text { financial plans. } \\
\text { Ensuring liquidity and profitability of corporation, i.e. } \\
\text { fulfillment of financial obligations at a certain point in } \\
\text { time. Identification of crisis phenomena and } \\
\text { development of countermeasures. }\end{array}$ \\
\hline Objects & Business activity. & $\begin{array}{l}\text { Finance, financial flows and capital structure of } \\
\text { corporation. }\end{array}$ \\
\hline Actors & $\begin{array}{l}\text { Corporations' personnel acting within the limits of terms of } \\
\text { reference. }\end{array}$ & $\begin{array}{l}\text { Qualified persons (designated representatives), } \\
\text { specializing departments staff members }\end{array}$ \\
\hline $\begin{array}{l}\text { Application } \\
\text { results }\end{array}$ & $\begin{array}{l}\text { Management decisions that improve corporation's } \\
\text { performance. }\end{array}$ & $\begin{array}{l}\text { Improvement of corporation's efficiency and forecast of } \\
\text { decision-making results. }\end{array}$ \\
\hline
\end{tabular}

Source: provided by the authors V. V. Manuylenko, M.A. Shebzukhova 
Table 2. Comparative analysis of strategic and short term financial controlling in corporations

\begin{tabular}{|c|c|c|}
\hline Criteria & \multicolumn{1}{|c|}{ Strategic financial controlling } & \multicolumn{1}{c|}{ Short term financial controlling } \\
\hline Time horison & \multicolumn{1}{|c|}{ Midle and long term } & \multicolumn{1}{c|}{ Short term } \\
\hline Main goals & $\begin{array}{l}\text { Crisis prevention policy, strategic goals setting, } \\
\text { analysis of the corporation's internal and external } \\
\text { environment, timely threats identification }\end{array}$ & $\begin{array}{l}\text { ensuring liquidity and profitability in corporations, } \\
\text { financial controlling management, determination of } \\
\text { indicators in accordance with the established current goals }\end{array}$ \\
\hline Targets & $\begin{array}{l}\text { Comparison of planned and actual indicators' } \\
\text { values, corporation's performance analysis, } \\
\text { determination of the main indicators in } \\
\text { accordance with the established strategic goals }\end{array}$ & $\begin{array}{l}\text { Comparison of planned and actual indicators' values, } \\
\text { detection of reasons that led to deviations of planned and } \\
\text { actual indicators' values, analysis of deviations impact on } \\
\text { current plans implementation }\end{array}$ \\
\hline Sources of information & External environment & \multicolumn{1}{c|}{ Corporation's indicators } \\
\hline Uncertainty & High & high \\
\hline Detailed breakdown & Low & \multicolumn{1}{c}{ low } \\
\hline
\end{tabular}

Source: provided by the authors V. V. Manuylenko, M.A. Shebzukhova

Table 3. Classification of universal and special methods of financial controlling in the context of its forms and types

\begin{tabular}{|c|c|c|c|}
\hline \multicolumn{2}{|c|}{ Financial controlling } & \multicolumn{2}{|c|}{ Methods } \\
\hline Forms & Types & Universal & Special \\
\hline \multicolumn{4}{|c|}{ Traditional } \\
\hline Strategic planning & Strategic & $\begin{array}{l}\text { Risk analysis, competition portfolio, } \\
\text { PEST-, SWOT-, CVP-analysis, BCG } \\
\text { matrix, synthesis, long-term forecasting, } \\
\text { planning }\end{array}$ & $\begin{array}{l}\text { Analysis of: opportunities, business } \\
\text { reorganization, efficiency, } \\
\text { business processes reengineering, strategic maps } \\
\text { creation }\end{array}$ \\
\hline Internal control & Short term & $\begin{array}{l}\text { Budgeting, financial analysis, } \\
\text { ABC-analysis, synthesis, benchmarking, } \\
\text { short- and medium-term planning }\end{array}$ & $\begin{array}{l}\text { Early detection system and identification of } \\
\text { bottlenecks, internal control with operational map } \\
\text { creation }\end{array}$ \\
\hline Analysis & External & Analysis of facts, events and deviations & $\begin{array}{l}\text { Analysis of facts, events, deviations and early } \\
\text { detection system }\end{array}$ \\
\hline \multicolumn{4}{|l|}{ Alternative } \\
\hline Monitoring & $\begin{array}{c}\text { Risk } \\
\text { controlling }\end{array}$ & Sensitivity analysis, Monte Carlo, expertise & $\begin{array}{l}\text { Comprehensive analysis of internal and external } \\
\text { environment, risk profile creation }\end{array}$ \\
\hline $\begin{array}{l}\text { Logical-linguistic } \\
\text { model }\end{array}$ & Situational & Logical-linguistic model & Situational analysis \\
\hline Observation & $\begin{array}{c}\text { Self } \\
\text { controlling }\end{array}$ & Monitoring & Timely express analysis \\
\hline $\begin{array}{l}\text { Tax control and } \\
\text { planning }\end{array}$ & Tax & Dimential, temporal analysis of taxes & $\begin{array}{l}\text { Analysis of the tax burden and control over } \\
\text { correct tax calculation }\end{array}$ \\
\hline $\begin{array}{l}\text { Block chain, Big Data, } \\
\text { artificial intelligence, } \\
\text { cloud technologies, } \\
\text { SaaS, computer } \\
\text { learning }\end{array}$ & Digital & $\begin{array}{lc}\text { Methodology } & \text { for validation of } \\
\text { technological feasibility of controlling } \\
\text { digitalization }\end{array}$ & Model for digital controlling platform \\
\hline
\end{tabular}

Source: provided by the authors V. V. Manuylenko, M.A. Shebzukhova

- the author's position on correlation between financial controlling and financial control is articulated and is expressed in the fact that financial controlling and internal control in corporations are essentially a system for collecting and processing information about the status of corporation's achievement of planned goals that is aimed at identifying and eliminating negative deviations. However, financial controlling, in contrast to financial control, is future focused and ensures achievement of the set goals at the lowest cost and is a part of financial decisions making;

- the following types of both standard and alternative financial controlling in correlation with their forms are presented: standard (strategic - strategic planning, operational - internal control, external - analysis) and alternative (risk-controlling - monitoring, situational - logical-linguistic model, self-control - observation, tax - tax control, tax planning);

a comparative analysis of strategic and short term types of financial controlling was carried out according to criteria such as: time horizon, main goals, objectives, sources of information, uncertainty, detailing - Table 2, which demonstrates that strategic controlling is based on self-control, is aimed at the future, creates new potentials for proficient corporation's operation in the long term and defines goals and objectives for operational controlling; operational controlling is based on external control, aimed at a certain sort term result and provides solutions for quantitative assessment of liquidity and profitability. 


\subsection{In the Methodological Field of Research:}

- it is stated that in order to achieve impartial financial controlling conduct in corporations it is necessary to consider its theoretical and methodological nature and include a set of methods, techniques and tools required for its implementation;

- it is important to take into account while preparing methodological toolkit for financial controlling that financial controlling adjusts designated goals to the current and future financial periods; its methods, tools and models are aimed to "create future" and manage future to ensure long-term performance of a corporation, whereas financial control, on the contrary, is focused on the past and reveals deviations between the planned and actual values of indicators;

- universal methods of financial controlling in various countries have been characterized, bearing in mind their size, i.e. in Russia, Germany and the United States financial controlling is implemented in corporations, holdings, financial and industrial groups and large diversified companies, whereas in Poland it is applied in small and medium-sized businesses and large corporations;

- it was determined that the substance of financial controlling methods depends on the purpose of its types (methods of strategic and operational financial controlling and other) that had its input into classification of its general and special methods in the context of forms and types - Table 3.

Efficient financial controlling in corporations is granted by an optimal combination of universal and special methods implemented in the context of its individual types and forms. That ensures integrated approach to its conduct.

\section{Discussions}

Considering long term expectations, one of the key areas that ensures advanced conduct of financial controlling conduct in corporations is employment of international financial reporting standards (IFRS). Their application in financial controlling system can be justified with the following: disclosure of information about an enterprise; easy comparability that works for as competent as possible evaluation of reporting and therefore corporations' performance in different parts of the world; also it allows evaluating the results of corporations' performance in different periods, and comparison of efficiency and profitability.

Russian financial controlling system is at its early development stage and requires attraction of the best world's practices. For example, in Germany, financial controlling has been developing for about 50 years. E. Mayer [30] defined it as internal control, which suggests certain provisions - terms of reference - for all employees in a corporation. Considering the main goal of financial controlling in corporations, which is management and profit planning, each specialist independently practices self-control. In England, corporate financial controlling is a part of universally accepted business practice under the "Company Acts" rules. In the United States, financial controlling started before the formation of the country, and was a borrowed experience from the basic rules of business development "Company Acts" rules (England, 1700). As a result, two contradictory models of financial controlling - English/American and German - have been functioning since then.

English/American model of controlling pursues tasks that are concentrated mainly on accounting, planning and analysis issues (making up and developing plans, comparing actual results with planned ones, informing management about performance results at all administration levels, constant analysis of factors and their impact on the corporation's activities). In the German model, financial controlling solves a set of tasks for analysis, planning, management and control (long-term/strategic planning coordination, internal information service, conducting certain economic researches). Thus, the German model of financial controlling includes planning tasks using target estimation control based on management accounting information, and in the United States, financial controlling is mostly merged with financial management.

Russian corporations carry out scrupulous planning and control procedures, pay great attention to ensured profitability, liquidity and diagnostic approach, which prevents them from leaning to either to the English/American or German models. The criteria for corporation's satisfactory performance in the short-term are financial performance and liquidity indicators, and in the long-term that is capital generation. N.N. Zhilina and T.S. Zagidullina [31] are sure that Russian corporations do not utilize German model precisely, and in most cases they just copy but do not adopt best international methods and techniques. It is apparent that Russian corporations should endorse main universal provisions of financial controlling theory based on efficient synergy of international and national experience.

\section{Conclusions}

Thus, modern theory of financial controlling in corporations should include:

- understanding essential definition of "financial controlling" in corporations as financial management system that identifies threats and timely prevents them; takes into account external and internal factors in conditions of uncertainty and risk by means of a set of methods that shift performance of corporation's 
structural divisions towards efficiency adapted to future changes and generally focused on ensuring and achieving overall well-organized performance;

- considering the main difference between financial controlling and financial control, i.e. understanding its employment for managing the future so as to ensure long term functioning of a corporation;

- establishment of a hierarchical relevance between forms and types of financial controlling, where form is a broader concept, which represents external characteristics of a certain financial controlling, whereas a type represents its component according to the certain functional characteristics;

- identification of alternative types and corresponding forms of financial controlling and their characteristics (risk controlling - monitoring, situational - logical and linguistic model, self-control - observation, tax - tax control, planning, digital - block chain, Big Data, artificial intelligence, cloud technologies, SaaS, machine learning etc.);

- break down of financial controlling methods by types and forms, like follows: universal methods (short-term: budgeting, financial analysis, ABC-analysis, synthesis, benchmarking, short- and medium-term planning, etc.), and special methods (short-term: early detection system and identification of bottlenecks, internal control with operational map creation, etc.), where they complement each other, justifying the need for their complex application.

Possible successful development of the modern theory on financial controlling in corporations at a new level is possible in the following areas:

- Creation and promotion of digital forms and types of financial controlling in corporations, based on their digital strategy;

- adjustment of the best world's practices during exercising of financial controlling forms and types;

- achieving best combination of standard and alternative forms and types of financial controlling, considering the purpose and objectives of its conduct;

- development of its alternative type - self-control, taking into account the best world's practice;

- complex application of universal and special methods, that complement each other during financial controlling conduct;

- management of risks via risk-controlling improvement and advancement, which at the same time might be grounded in the concept of end-to-end risk management in commercial organizations taking into consideration digitization of the Russian economy [32], as well as tools for strategic assessment of financial risks in corporations based on stochastic modeling [33];

- identification of financial controlling features when it is conducted in corporations with different financial status; differentiation of financial controlling conduct models depending on business and size of corporations;

- ensuring its synergy with IFRS;

- development of tools for detecting future deviations of actual indicators' values from designated ones, including those that are operating on the basis of probability assessment of the forecasted deviation in the general matter and with monetary approach [34].

Applying proposed theoretical and methodological tools, corporations may carry out financial controlling based on the best combination of its standard and alternative forms and types, attracting an appropriate set of universal and special methods, and taking into account the world's best practice, which proves the working hypothesis of the study. Surely, the proper and well-grounded application of main provisions of financial controlling in corporations theory at a new level that integrates world's best practices might ensure its efficient practical conduct.

\section{REFERENCES}

[1] Yu. P. Aniskin, A. M. Pavlova. Planning and controlling, Omega-L, Moscow, 2013, 336 p.

[2] E. M. Korotkov. Crisis management, 2nd ed., with additions and revised, INFRA-M, Moscow, 2008, 619 p.

[3] M. Sedliacikova, V. Vacek, E. Sopkova. How Slovak small and medium enterprises perceive financial controlling, Procedia Economics and Finance, Vol.26, 82-85, 2015. https://doi.org/10.1016/S2212-5671(15)00842-4

[4] W. Ye, J. Dong. Financial control supports the co-evolution of product services and employee competence: take haier group as an example, Procedia CIRP, Vol.83, 808-813, 2019. https://doi.org/10.1016/j.procir.2019.05.005

[5] G. Bella, P. Mattana. Chaos control in presence of financial bubbles, Economics Letters, Vol.193, 109314, 2020. https://doi.org/10.1016/j.econlet.2020.109314

[6] D. P. Hampson, Sh. Gong, Y. Xie. How consumer confidence affects price conscious behavior: The roles of financial vulnerability and locus of control, Journal of Business Research, Vol.132, 693-704, 2020. https://doi.org/10.1016/j.jbusres.2020.10.032

[7] Y. Li, X. Li, E. Xiang, H. G. Djajadikerta. Financial distress, internal control, and earnings management: Evidence from China, Journal of Contemporary Accounting \& Economics, Vol.16, No.3, 100210, 2020. https://doi.org/10.1016/j.jcae.2020.100210

[8] M. Zachariadis, G. Hileman, S. V. Scott. Governance and control in distributed ledgers: Understanding the challenges facing block chain technology in financial services, Information and Organization, Vol.29, No.2, 105-117, 2019. https://doi.org/10.1016/j.infoandorg.2019.03.001 
[9] C. Strömbäck, T. Lind, K. Skagerlund, D. Västfjäll, G. Tinghög. Does self-control predict financial behavior and financial well-being? Journal of Behavioral and Experimental Finance, Vol.14, 30-38, 2017. https://doi.org/10.1016/j.jbef.2017.04.002

[10] C. Strömbäck, K. Skagerlund, D. Västfjäll, G. Tinghög. Subjective self-control but not objective measures of executive functions predicts financial behavior and well-being, Journal of Behavioral and Experimental Finance, $\quad$ Vol.27, $100339, \quad 2020$. https://doi.org/10.1016/j.jbef.2020.100339

[11] K. Sekścińska, J. Rudzinska-Wojciechowska, D. Jaworska. Self-control and financial risk taking, Journal of Economic Psychology, Vol.85, 102386, 2021. https://doi.org/10.1016/j.joep.2021.102386

[12] A. P. M. Monteiro, J. A. M. Vale, C. L. M. Cepêda, E. M. de Almeida Leite. Internal Control System Quality and Decision-Making Success: The Role of the Financial Information Quality, Universal Journal of Accounting and Finance, Vol.9, No.3, 285-294, 2021. https://doi.org/10.13189/ujaf.2021.090302

[13] S. K. Dey, D. Sharma. Nexus between Corporate Governance and Financial Performance: Corroboration from Indian Banks, Universal Journal of Accounting and Finance, Vol.8, No.4, 140-147, 2020. https://doi.org/10.13189/ujaf.2020.080406.

[14] R. Mann, R. Mayer. Controlling for beginners. Profit management system, ed. by V. B. Ivashkevich, transl. from English by Yu. G. Zhukova, Finance and statistics, Moscow, 2014, 304 p.

[15] A. M. Karminsky, S. G. Falko, A. A. Zhevaga, N. Yu. Ivanova. Controlling, Forum, Moscow, 2013, 336 p.

[16] T. A. Zolotko. Financial controlling and monitoring of cash flows in corporations: abstract dis. ... Ph.D. in Economics: 08.00.10, Volgograd State University, Volgograd, 2005, 24 p.

[17] R. Adams. Introduction to auditing, transl. from English, ed. by Ya. V. Sokolova, Audit, UNITI, Moscow, 1995, 398 p.

[18] V. V. Burtsev. Controlling of finance: options and directions, Management today, No.5, 12-15, 2003.

[19] M. A. Vakhrushina. Problems and development issues of Russian management accounting, International accounting, Vol.33, 12-23, 2014.

[20] I. V. Pogodaeva, I. T. Kovalenko. Internal financial control in the organization's management system, II International Scientific and Practical Conference "Modernization of Economy and Management: Collection of Articles", Stavropol, Russia, February 27, 223-225, 2014.

[21] M. A. Pavlenkov. Controlling in the management system, Voprosy ekonomiki, No.4, 69-73, 2006.

[22] S. G. Falko. Controlling in Russia: current state and development prospects, Collection of scientific papers of the IV Congress in Prague "Controlling in small and medium-sized enterprises", Prague, Czech Republic, April $25,3-7,2014$

[23] E. A. Gorelchenko. Integration of risk controlling into the financial management of the company: abstract dis. ... Ph.D. in Economics: 08.00.10, Saint Petersburg State University of Economics and Finance, St. Petersburg, 2009, 20 p.

[24] V. V. Manuylenko, M. A. Shebzukhova. Risk controlling as a way of regulating shadow processes in Russian corporations: problems and prospects, Science and business: ways of development, No.5 (107), 169-171, 2020.

[25] N. G. Danilochkina. Controlling as an enterprise management tool, UNITY-DANA, Moscow, 2015, 279 p.

[26] N. S. Necheukhina, N. A. Polozova, T. A. Buyanova. Controlling as a mechanism for increasing efficiency of industrial enterprises in digital technologies environment, Scientific and technical news of SPbSPU. Economic sciences, No.4, 176-186, 2017.

[27] D. A. Batalov, M. S. Rybyantseva. Methods and tools for short-term and strategic controlling, Polythematic network electronic scientific journal of the Kuban State Agrarian University, No.67, 211-229, 2011.

[28] I. S. Plakidin. Historical aspects of the origin and development of the concept of controlling in foreign countries, Finance and Credit, No.20, 65-74, 2010.

[29] E. V. Ponomareva. Controlling in the enterprise, Publishing house of the Saint Petersburg University of Management and Economics, St. Petersburg, 2012, 188 p.

[30] E. Mayer. Controlling as a system of thinking and management, transl. from German by Yu.G. Zhukova, S.N. Zaitsev, ed. by S.A. Nikolaeva, Finance and Statistics, Moscow, 1993, 96 p.

[31] N. N. Zhilina, T. S. Zagidullina. Foreign controlling models and possibilities of their application in Russia, International Accounting, No.36, 62-66, 2011.

[32] V. A. Kunin, D. Mikhailovsky. The concept of end-to-end risk management of commercial business organizations under conditions of digitalization of Russian economy, Proceedings of the III International Scientific and Practical Conference "Digital Economy and Finances" (ISPC-DEF 2020), St. Petersburg, Russia, March 19-20, 12-16, 2020.

[33] V. V. Manuylenko, D. A. Ryzin, N. V. Gryzunova, O. B. Bigday, O. V. Mandrytsa. Toolset for financial risk strategic assessment in corporations based on stochastic modeling, Amozonia Investiga, Vol.9, No.28, 451-464, 2020.

[34] Yu.Yu. Kochinev, D. G. Rodionov. Probabilistic assessment of projected deviation in a general population when applying the monetary method, Proceedings of the 32nd International Business Information Management Association Conference, IBIMA 2018 - Vision 2020: Sustainable Economic Development and Application of Innovation Management from Regional expansion to Global Growth, Seville, Spain, November 15-16, 49194924, 2018 